
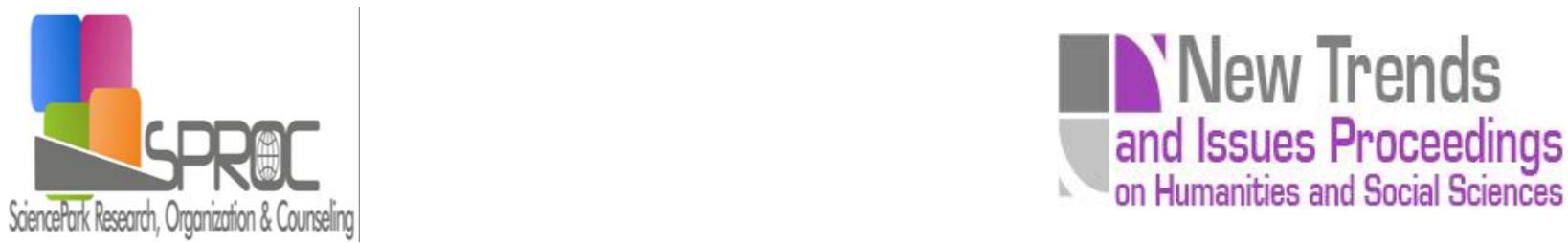

\title{
Features of psychological adaptation of training future teachers of Physical Culture
}

\author{
Antonina Soboleva ${ }^{*}$ \\ Rezeda Khasanova ${ }^{b}$ \\ Vladimir Andreev ${ }^{\mathrm{c}}$ \\ Tatyana Sarycheva ${ }^{d}$ \\ Ludmila Smaglye
}

Suggested Citation:

New Trends and Issues Proceedings on Humanities and

Social Sciences.

Abstract

Rezeda, Khasanova

E-mail address 
New Trends and Issues Proceedings on Humanities and Social Sciences.

1. Introduction 
New Trends and Issues Proceedings on Humanities and Social Sciences. 
New Trends and Issues Proceedings on Humanities and Social Sciences.

2. Methodology of the research 
New Trends and Issues Proceedings on Humanities and Social Sciences.

3. Research results 
New Trends and Issues Proceedings on Humanities and Social Sciences.

4. Discussion 
New Trends and Issues Proceedings on Humanities and Social Sciences. 
New Trends and Issues Proceedings on Humanities and Social Sciences.

\section{Conclusion}


New Trends and Issues Proceedings on Humanities and Social Sciences. 


\section{References}

Procedia-Social and Behavioral Sciences 203

Psihologiya obucheniya

Physical culture: education, education and training, 1

Procedia-Social and Behavioral Sciences 200

St. Petersburg, publ: Prime Evroznak 479

Theoretical and experimental psychology 5

Procedia-Social and Behavioral Sciences 112

Tertiary Education and Management 18

studies 38

Educational

International Journal of Intercultural Relations 35 